\title{
ESTUDO DOS EFEITOS FISIOLÓGICOS IN VITRO DE DIFERENTES BASES DE MEIO DE CULTURA E REGULADORES VEGETAIS EM EUCALIPTO
}

\author{
Débora de Araújo Mattos ${ }^{1}$ \\ Roberta Borges dos Santos ${ }^{2}$ \\ Walderez Moreira Joaquim ${ }^{3}$
}

\begin{abstract}
Resumo: O cultivo in vitro de Eucalipto surgiu com a necessidade de clonar híbridos que possuam elevado valor econômico na indústria. Nesse contexto, objetivou-se avaliar a influência de diferentes meios de cultura (JADS e MS) e citocininas (BAP, meta-Topolin e Kinetin) em três concentrações (0,1; 0,2; 0,4 mg. $L^{-}$ 1) no processo de multiplicação in vitro de dois híbridos de Eucalyptus grandis $x$ Eucalyptus urophylla, nomeados como Clone 1 e Clone 2. Os resultados indicaram que os tratamentos em meio MS foram superiores ao meio JADS, e todos os tratamentos suplementados com Kinetin foram iguais ou semelhantes aos tratamentos sem regulador vegetal. Assim, o melhor tratamento para o Clone 1 foi em base de meio MS suplementado com 0,4 mg. $\mathrm{L}^{-1}$ de BAP, enquanto que para o Clone 2 foram os tratamentos em meio MS suplementados tanto com 0,2 mg. $\mathrm{L}^{-1}$ quanto $0,4 \mathrm{mg} \cdot \mathrm{L}^{-1}$ de $B A P$.
\end{abstract}

Palavras-chave: Micropropagação; Eucalipto; BAP; meta-TOPOLIN; KINETIN.

\footnotetext{
${ }^{1}$ Bacharelado em Ciências Biológicas/UNIVAP, Brasil. E-mail: debora_araujo.mattos@yahoo.com.br.

2 Laboratório de Micropropagação/FIBRIA, Brasil. E-mail: roberta.santos@fibria.com.br.

3 Instituto de Pesquisa e Desenvolvimento/UNIVAP, Brasil. E-mail: wal@univap.br.
} 